\title{
Identification of NDUFAF1 in mediating K-Ras induced mitochondrial dysfunction by a proteomic screening approach
}

\author{
Peng Wang ${ }^{1,2, *}$, Ming Song ${ }^{1, *}$, Zhao-lei Zeng ${ }^{1}$, Chao-feng Zhu ${ }^{1}$, Wen-hua Lu ${ }^{1}$, \\ Jing Yang ${ }^{1}$, Ming-zhe Ma ${ }^{1}$, A-min Huang ${ }^{1}$, Yumin $\mathrm{Hu}^{1}$, Peng Huang ${ }^{1,3}$ \\ ${ }^{1}$ Sun Yat-sen University Cancer Center, State Key Laboratory of Oncology in South China, Collaborative Innovation Center of \\ Cancer Medicine, Guangzhou, China \\ ${ }^{2}$ Department of Emergency Medicine, Sun Yat-sen Memorial Hospital, Guangzhou, China \\ ${ }^{3}$ Department of Translational Molecular Pathology, The University of Texas M.D. Anderson Cancer Center, Houston, TX, USA \\ *These authors have contributed equally to this work
}

Correspondence to:

Yumin Hu, e-mail: huym@sysucc.org.cn

Peng Huang, e-mail: huangpeng@sysucc.org.cn

Keywords: K-Ras, mitochondria, NDUFAF1, glycolysis

Received: July 21, $2014 \quad$ Accepted: December 17, $2014 \quad$ Published: February 27, 2015

\section{ABSTRACT}

Increase in aerobic glycolysis and mitochondrial dysfunction are important biochemical features observed in human cancers. Recent studies suggest oncogenic K-Ras can cause suppression of mitochondrial respiration and up-regulation of glycolytic activity through a yet unknown mechanism. Here we employed proteomic approach and used a K-Ras ${ }^{G 12 V}$ inducible cell system to investigate the impact of oncogenic K-Ras on mitochondria and cell metabolism. Mitochondria isolated from cells before and after K-Ras induction were subjected to protein analysis using stable isotope labeling with amino acids (SILAC) and liquid chromatography coupled with mass spectrometry (LC-MS). 70 mitochondrial proteins with significant expression alteration after K-Ras induction were identified. A majority of these proteins were involved in energy metabolism. Five proteins with significant decrease belong to mitochondrial respiratory chain complex I. NADH dehydrogenase 1 alpha subcomplex assembly factor 1 (NDUFAF1) showed most significant decrease by $50 \%$. Such decrease was validated in primary human pancreatic cancer tissues. Knockdown of NDUFAF1 by siRNA caused mitochondrial respiration deficiency, accumulation of NADH and subsequent increase of glycolytic activity. Our study revealed that oncogenic K-Ras is able to induce significant alterations in mitochondrial protein expression, and identified NDUFAF1 as an important molecule whose low expression contributes to mitochondrial dysfunction induced by K-Ras.

\section{INTRODUCTION}

Many cancer cells preferentially use glycolysis for generation of ATP and metabolic intermediates even in the presence of oxygen, and such metabolic feature is regarded as a hallmark of cancer [1]. Normal cells show active mitochondrial respiratory function and use the energy-efficient oxidative phosphorylation as the main route to generate ATP. The phenomenon of active aerobic glycolysis in cancer cells is known as Warburg effect, and is manifested as active glucose uptake and increased lactate production [2-4]. Such alterations in energy metabolism in cancer cells are often associated with mitochondrial dysfunction [5]. Importantly, recent studies suggest that metabolic alterations in cancer cells seem to be associated with activation of certain oncogenic signals (such as activating mutations in Ras oncogene) or loss of tumor suppressor function (such as loss or mutation of p53). Of note, the oncogenic Ras proteins including $\mathrm{K}-\mathrm{Ras}, \mathrm{H}-\mathrm{R}$ as and N-Ras are frequently mutated in human cancers. K-Ras is normally associated with the membrane lipid rafts and acts as an effector for signal transduction. Recent studies showed that K-Ras is able to translocate to mitochondria when phosphorylated [6]. Other studies 
showed that K-Ras is able to cause mitochondria dysfunction and regulate glucose metabolism [7-9], yet the detailed molecular mechanisms of mitochondria dysfunction induced by K-Ras remains to be investigated.

Recent advance in proteomic technology has enabled detail analysis of protein molecules that contribute to metabolic alterations in cancer and other diseases. Application of mitochondrial proteomics has shed new light on diagnosis and treatment of mitochondria dysfunction associated diseases, and allowed identification and quantification of biomarkers for the early diagnosis and pathologies [10, 11]. Stable isotope labeling with amino acids (SILAC) has become a pivotal tool to study changes in protein abundance in many different biological processes such as detection of biomarkers in tissue samples, the regulation of cell signaling, and the characterization of protein interactions. The current study used SILAC technology as initial screening for candidate proteins involved in mitochondrial dysfunction induced by K-Ras activating mutation $\left(\mathrm{K}-\mathrm{Ras}^{\mathrm{G} 12 \mathrm{~V}}\right)$.

The main goals of this study were to identify mitochondrial proteins that may be involved in the metabolic alterations induced by constitutive activation of K-Ras, to investigate underlying mechanism, and to evaluate the clinical relevance. We have previously established a doxycycline inducible cell system with $\mathrm{K}_{-} \operatorname{Ras}^{\mathrm{G} 12 \mathrm{~V}}$ expression vector (T-Rex/293), which induced mitochondrial dysfunction upon expression of K-Ras ${ }^{\mathrm{G} 12 \mathrm{~V}}$ protein [9]. Since abnormal K-Ras activation and the associated mitochondrial dysfunction and metabolic shift are frequently observed in human cancer, the use of the current experimental system enabled us to identify a key molecular player that seems essential to maintain the metabolic changes in K-Ras-transformed cells. In this study, we isolated mitochondria from T-Rex/293 cells before and after induction of K-Ras ${ }^{\mathrm{G} 12 \mathrm{~V}}$, followed by identification of mitochondrial proteins with significant changes using SILAC coupled with LC-MS analysis. A number of subunits of mitochondrial respiratory chain complex I were identified with significantly decreased protein ratios. We found that NDUFAF1 showed the most significant decrease after K-Ras ${ }^{\mathrm{G} 12 \mathrm{~V}}$ induction and such decrease was also observed in clinical samples of pancreatic cancer tissues. The role of NDUFAF1 decrease in mediating mitochondrial dysfunction was further confirmed by siRNA knockdown, which led to inhibition of mitochondrial complex I activity and up-regulation of glycolysis.

\section{RESULTS}

\section{K-Ras activation causes mitochondrial dysfunction}

We have previously established a tetracyclineinducible K-Ras ${ }^{\mathrm{G} 12 \mathrm{~V}}$ expression cell system [9]. In this system, expression of K-Ras ${ }^{\mathrm{G} 12 \mathrm{~V}}$ protein can be induced by addition of doxycycline and a large portion of K-Ras ${ }^{\mathrm{G} 12 \mathrm{~V}}$ protein is localized to the mitochondria, leading to changes of mitochondrial function (9). Since mitochondria play a critical role in carrying out oxidative phosphorylation and normally produces the majority of cellular ATP, we first measured ATP generation and oxygen consumption before and after K-Ras ${ }^{\mathrm{G} 12 \mathrm{~V}}$ induction. As shown in Figure 1A, K-Ras ${ }^{\mathrm{G} 12 \mathrm{~V}}$ expression caused a decrease of ATP generation in a time-dependent manner. Mitochondrial respiratory chain activity was also inhibited as evidenced by substantial decrease in oxygen consumption rate after K-Ras activation for both $24 \mathrm{hrs}$ and $48 \mathrm{hrs}$ (Figure 1B). The Seahorse XF analyser further demonstrated that K-Ras activation caused significant decrease in both maximal respiration and basal respiration levels (Supplemental Figure 1). One important biochemical event associated with oxidative phosphorylation is the production of reactive oxygen species (ROS) due to electron leakage from the respiratory chain. We found that K-Ras activation resulted in an increase of ROS production detected by DCF-DA (Figure 1C). Substantial elevation of intracellular superoxide $\left(\mathrm{O}_{2}^{-}\right)$was also detected by MitoSOX Red mitochondrial superoxide indicator (Supplemental Figure 2A), indicating the source of ROS generation form mitochondrial electron leakage. We also examined the ultrastructure of mitochondria by transmission electron microscope (TEM). Normal tubular morphology of mitochondria was observed in control cells without K-Ras induction (Figure 1D). In contrast, swollen mitochondria were seen after K-Ras induction for 24 hrs (Figure 1E). Rotenone, a known inhibitor of mitochondrial respiratory chain complex I was used to treat the cells without K-Ras induction. As shown in Figure 1F, incubation with $100 \mathrm{nM}$ rotenone for $36 \mathrm{~h}$ also caused alterations of mitochondrial morphology similar to that of cells with K-Ras ${ }^{\mathrm{G} 12 \mathrm{~V}}$ induction. Taken together, these results suggest that $\mathrm{K}$-Ras activation is able to cause significant alterations in mitochondrial function and ultrastructure.

\section{Proteomic analysis of mitochondrial proteins using SILAC}

To identify the potential mitochondrial proteins involved in mediating mitochondrial dysfunction induced by K-Ras, we used quantitative proteomics to analyze mitochondria proteome dynamics using stable isotope labeling with amino acids in cell culture (SILAC). In consistence with our previous finding that K-Ras protein was associated with mitochondria, western blotting analysis confirmed the increase of $\mathrm{K}-\mathrm{Ras}^{\mathrm{G} 12 \mathrm{~V}}$ expression in a time-dependent manner in the mitochondrial fraction after addition of doxycyline (Figure 2A). The purity of mitochondria was validated by organelle specific protein markers of different subcellular fractions. As shown in Figure 2B, after induction for $24 \mathrm{hrs}$, the mitochondrial fraction was highly enriched in mitochondrial markers such as VDAC (Voltage-dependent anion channel) and 

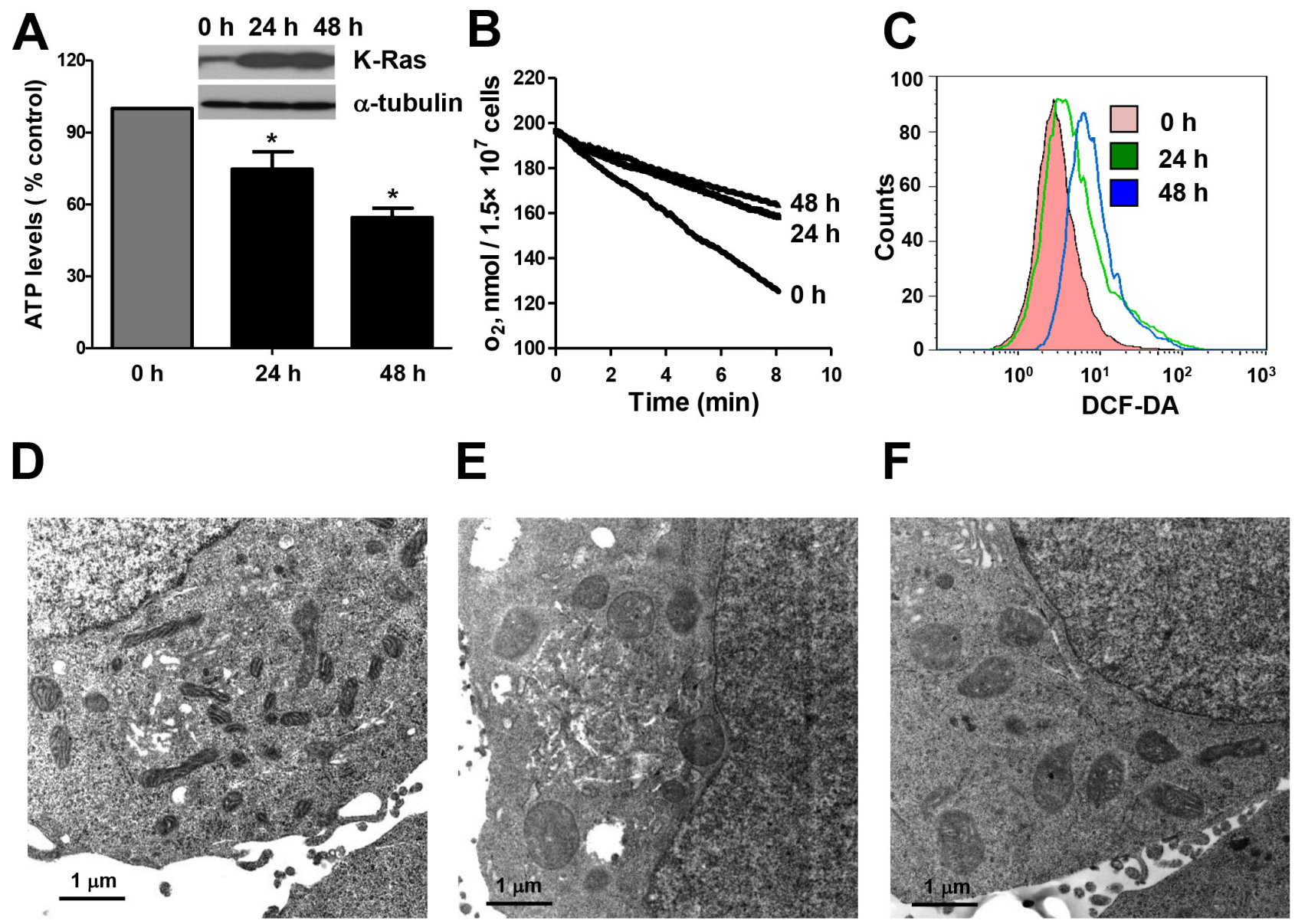

Figure 1: Expression of oncogenic K-Ras ${ }^{\mathrm{G} 12 \mathrm{~V}}$ caused mitochondria dysfunction and metabolic alterations. (A) ATP levels of T-Rex/293 cells before and after K-Ras ${ }^{\mathrm{G} 12 \mathrm{~V}}$ induction by doxycycoine for 24 and $48 \mathrm{hrs}$. Data are shown as mean \pm SD from three independent experiments, ${ }^{*} P<0.05$. (B) Decrease of oxygen consumption rate after K-Ras ${ }^{\mathrm{G} 12 \mathrm{~V}}$ induction for 24 and 48 hrs. (C) Increase of ROS level after K-Ras induction for 24 and 48 hrs detected by flow cytometry using DCF-DA. (D-F) Transmission electron microscopic analysis of mitochondria morphology. (D) Normal mitochondrial morphology of TRex/293 cell without K-Ras activation. (E) Alteration of mitochondrial morphology after K-Ras induction for $48 \mathrm{hrs}$. (F) Alteration of mitochondrial morphology after treatment of $100 \mathrm{nM}$ rotenone for $36 \mathrm{hrs}$.

cytochrome $\mathrm{C}$, while other markers such as tubulin (cytosol marker) and Bip (endoplasmic reticulum marker) were absent in the mitochondrial fraction, indicating that there was no detectable contamination of other organelles.

Figure $2 \mathrm{C}$ depicts the proteomic strategy using SILAC and LC-MS for discovery of changes in mitochondrial proteins associated with metabolic alteration induced by K-Ras. The T-Rex/K-Ras cells with and without K-Ras induction were labeled with the indicated stable isotopes and cultured for 10 passages before protein isolation and LC-MS analyses. Control cells without $\mathrm{K}$-Ras induction were cultured in isotope free medium (light density, $\mathrm{K}_{0} \mathrm{R}_{0}$ ). Cells with $\mathrm{K}$-Ras induction for $24 \mathrm{hrs}$ were cultured in $\left[{ }^{13} \mathrm{C}_{6}\right]$ arginine and 4,4,5,5-D4lysine labeled medium (Medium density, $\mathrm{K}_{4} \mathrm{R}_{6}$ ). Cells with K-Ras induction for $48 \mathrm{hrs}$ were cultured in $\left[{ }^{13} \mathrm{C}_{6}{ }^{15} \mathrm{~N}_{4}\right]$ arginine and $\left[{ }^{13} \mathrm{C}_{6},{ }^{15} \mathrm{~N}_{2}\right]$ lysine labeled medium (Heavy density, $\mathrm{K}_{8} \mathrm{R}_{10}$ ). Mitochondria isolated from cells labeled with light, medium and heavy isotopes were mixed in a
1:1:1 ratio based on total protein concentrations. The mixed mitochondria were then lysed, properly digested to peptides, and then subjected to LC-MS/MS analysis. As shown in Figure 2D, the mass spectrum peaks of heavy and medium labeled proteins exhibited a corresponding shift according to their $\mathrm{m} / \mathrm{z}$ values compared with light proteins, indicating proper incorporation of isotopes into the cells with different status of K-Ras as anticipated.

\section{Identification of K-Ras-induced alterations in mitochondrial proteins}

The mass spectrum analysis was used to characterize and quantify the mitochondrial proteomic changes induced by K-Ras ${ }^{\mathrm{G} 12 \mathrm{~V}}$. As shown in Figure 3A, 614 mitochondria proteins were identified and quantified by LC-MS and SILAC. 544 mitochondrial proteins remained unchanged after K-Ras induction. 33 proteins showed a significantly increase and 37 proteins showed 

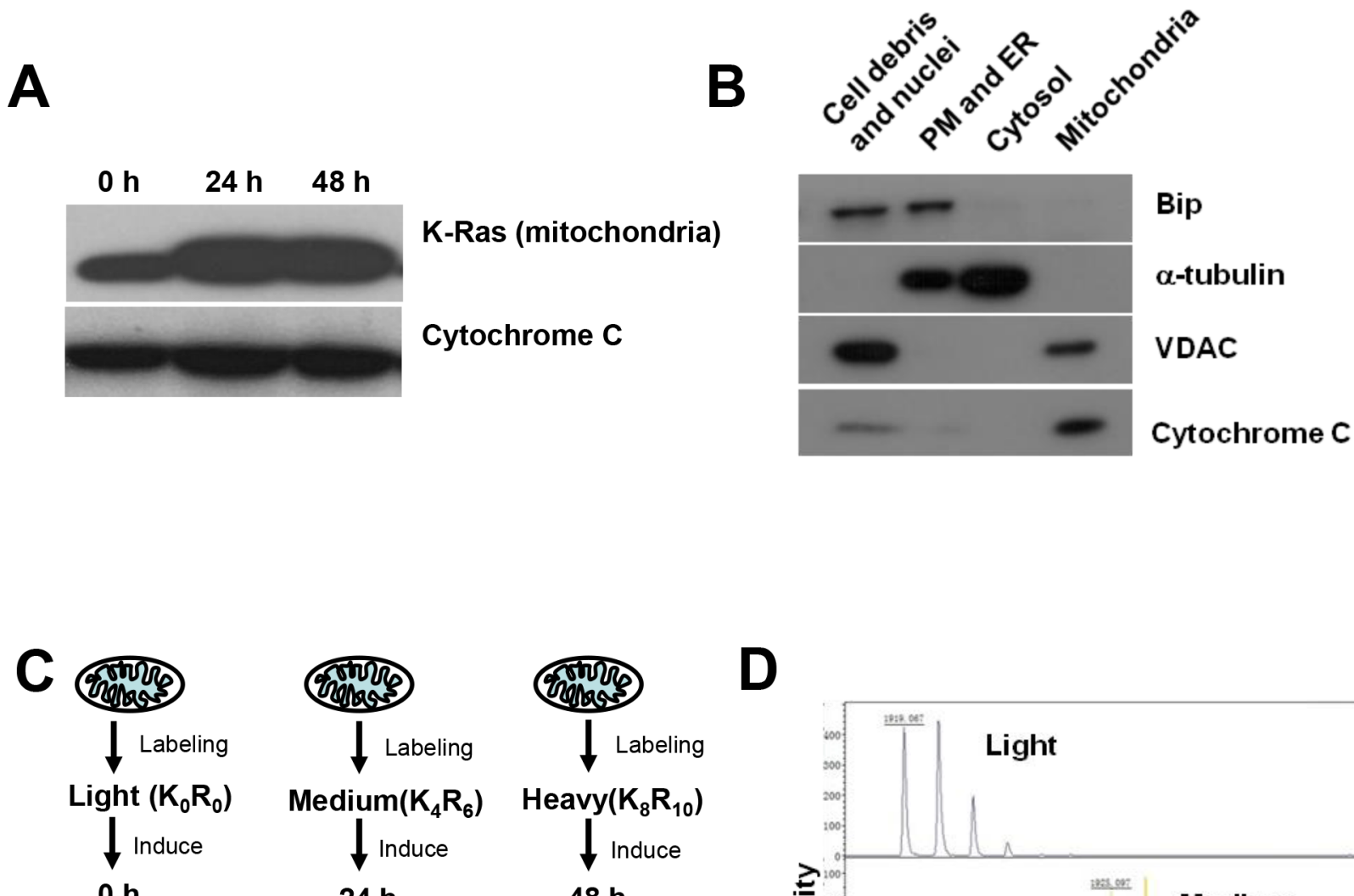

D

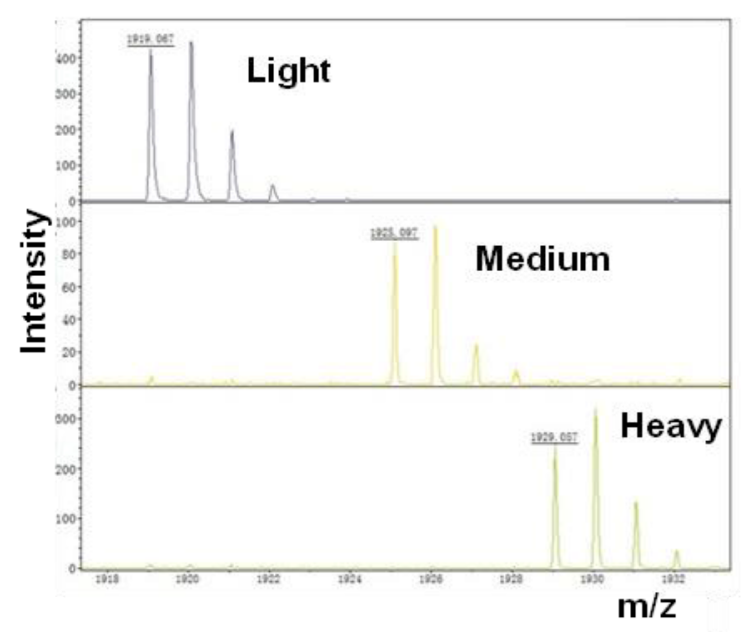

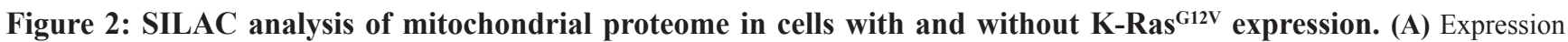
of K-Ras ${ }^{\mathrm{G} 12 \mathrm{~V}}$ in mitochondria after doxycycline induction for 24 and $48 \mathrm{hrs}$. Cytochrome $\mathrm{C}$ was used as loading control for mitochondria extracts. (B) Purity of mitochondrial protein extracts by immunoblotting analysis. Cellular fractions were prepared from T-Rex/293 cells after K-Ras activation for $24 \mathrm{hrs}$. Purity of subcellular fractions was determined by immunoblotting analysis using antibodies against mitochondrial localized marker VDAC and cytochrome C, cytoplasmic localized marker $\alpha$-tubulin, ER (endoplasmic reticulum) localized marker Bip. (C) Quantification and identification of mitochondrial proteins of T-Rex/293 cells before and after K-Ras induction by LC-MS. Cells were labeled with different isotopes as described in "Experimental procedures" under "Cell culture and isotopes labeling". Light, control cells without K-Ras induction. Medium and Heavy, cells with K-Ras induction for 24 hrs and 48 hrs, respectively. The mixed mitochondrial lysates were separated by SDS-PAGE and analyzed by Mass Spectrometry. (D) The mass spectrum peaks indicates the separation of mitochondrial proteins labeled with different isotopes.

a significant decrease when compared with the control sample without K-Ras induction. Among the 33 proteins with increased expression, 5 proteins were upregulated only at the early time point $(24 \mathrm{~h}) ; 15$ proteins increased only at $48 \mathrm{~h}$; and 13 proteins were upregulated at both $24 \mathrm{~h}$ and $48 \mathrm{~h}$. Among the 37 proteins with lower expression, 4 proteins were downregulated at $24 \mathrm{~h} ; 10$ proteins were downregulated only after $48 \mathrm{hrs}$, and 23 proteins decreased at both $24 \mathrm{~h}$ and $48 \mathrm{~h}$.
The protein density ratios (Figure 3B-3D) represent the relative abundance of proteins in cells with K-Ras induction compared with cells without induction $(\mathrm{H} / \mathrm{L}$ for $48 \mathrm{~h}, \mathrm{M} / \mathrm{L}$ for $24 \mathrm{~h}$ ), or cells with $48 \mathrm{hr}$ induction compared with cells with $24 \mathrm{hr}$ induction (H/M). The majority of proteins remained unchanged with the density distribution at 1:1 ratio. A small number of proteins showed significant change $(P<0.05)$, and suggested a possibility that these mitochondrial proteins might 

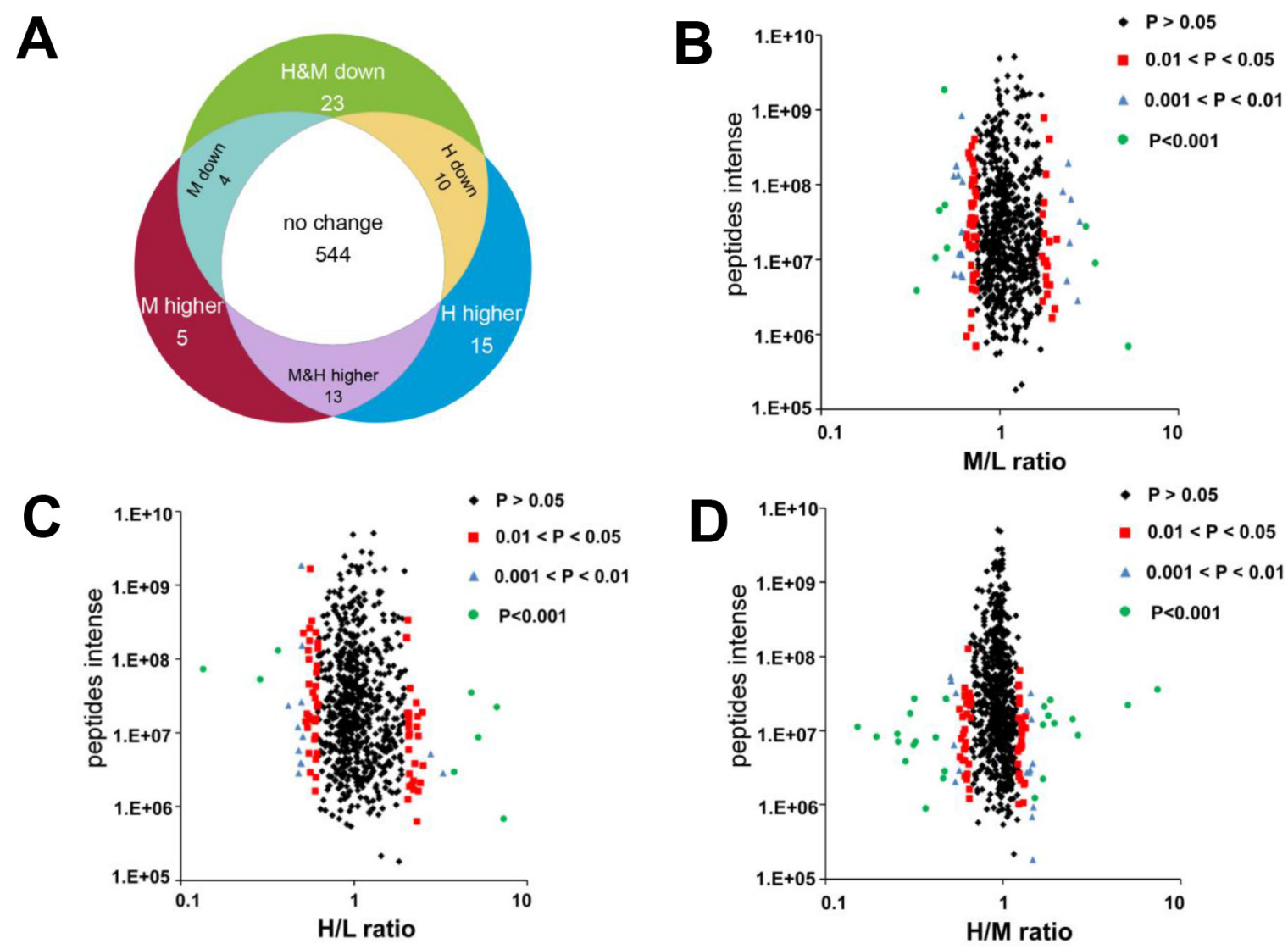

Figure 3: Effect of K-Ras ${ }^{\text {G12V }}$ activation on mitochondrial proteins expression profiles. (A) Venn diagrams depict 614 proteins identified and quantified by SILAC and LC-MS. 544 proteins remained unchanged. 70 proteins showed significantly altered expression in cells with K-Ras induction for 24 or $48 \mathrm{hrs}$ compared with control without K-Ras induction $(P<0.05)$. (B-D) Volcano plots showing protein ratios of each pair of cells indicated. H, K-Ras induction for $48 \mathrm{hrs}$. M, K-Ras induction for 24 hrs. L, control without $\mathrm{K}-\mathrm{Ras}$ induction.

contribute to the mitochondrial dysfunction and metabolic alterations induced by K-Ras activation. As shown in Table 1, K-Ras was identified in the mitochondrial proteome and its expression increased by 5.2 and 7.3 folds after induction for 24 and 48 hs, respectively ("M\&H higher", line 12). This was consistent with the findings in Figure 2A showing the increase of K-Ras protein in mitochondria, and thus served as a good validation of this proteomic analysis. We then used Panther (protein analysis through evolutionary relationships) analysis to investigate the biological pathways involved after K-Ras activation. As shown in Table 2, we identified 13 groups of proteins based on the biological function of these differentially expressed proteins after K-Ras induction. Of particular note, among the approximately 70 mitochondrial proteins that showed altered expression after K-Ras induction, 9 proteins are involved in generation of metabolite and energy precursors and 36 proteins are associated with metabolic process (Table 2 lines 9 and 10, respectively).

Because K-Ras activation caused a significant decrease in cellular oxygen consumption and ATP production (Figure 1), we further analyzed the group of 9 proteins involved in the generation of precursor metabolites and energy in order to identify the mitochondrial proteins contributing to K-Ras-induced metabolic alterations. Out of the 9 proteins in this group, 5 proteins belonged to the mitochondrial respiratory chain complex I, one protein was a subunit of complex III, and one belonged to complex IV (Table 3).

\section{Down regulation of NDUFAF1 in K-Ras- transformed cells and in pancreatic cancer tissues}

The results shown in Table 3 suggest that downregulation of certain complex I components, especially NADH dehydrogenase (ubiquinone) 1 alpha sub-complex assembly factor 1 (NDUFAF1), might play an important role in mediating mitochondrial dysfunction induced by K-Ras activation, since the expression of these protein subunits were significantly down-regulated. It is known that NDUFAF1 plays a key role in the assembly of mitochondrial complex I [12-14]. LC-MS analysis showed that the expression of NDUFAF1 was down-regulated by approximately $20 \%$ and $50 \%$ after K-Ras induction for $24 \mathrm{hrs}$ 
Table 1: Differential expression of mitochondrial proteins after K-ras activation

\begin{tabular}{|c|c|c|c|c|c|c|}
\hline Protein IDs & Protein Names & $\begin{array}{c}\text { Gene } \\
\text { Names }\end{array}$ & $\begin{array}{l}\text { Ratio M/L } \\
\text { Normalized }\end{array}$ & $\begin{array}{c}\text { Ratio } \\
\text { M/L } \\
p \text {-value }\end{array}$ & $\begin{array}{l}\text { Ratio H/L } \\
\text { Normalized }\end{array}$ & $\begin{array}{c}\text { Ratio H/L } \\
p \text {-value }\end{array}$ \\
\hline \multicolumn{7}{|l|}{ M\&H higher } \\
\hline IPI00024551 & UPF0480 protein C15orf24 & C15orf24 & 2.405 & 0.005 & 1.998 & 0.049 \\
\hline IPI00784366 & AP-2 complex subunit beta- 1 & AP2B1 & 1.954 & 0.026 & 2.338 & 0.021 \\
\hline IPI00059762 & Lysophospholipase-like protein 1 & LYPLAL1 & 3.416 & 0.001 & 2.352 & 0.021 \\
\hline IPI00908804 & $\begin{array}{l}\text { highly similar to ATP-binding cassette } \\
\text { sub-family D member } 3\end{array}$ & ABCD3 & 2.444 & 0.005 & 2.319 & 0.022 \\
\hline IPI00294472 & $\begin{array}{l}\text { Transmembrane emp } 24 \text { domain-containing } \\
\text { protein } 5\end{array}$ & TMED5 & 2.075 & 0.017 & 2.029 & 0.045 \\
\hline IPI00328840 & THO complex subunit 4 & THOC4 & 1.882 & 0.034 & 2.069 & 0.041 \\
\hline IPI00305289 & Kinesin-like protein KIF11 & KIF11 & 2.104 & 0.015 & 2.409 & 0.018 \\
\hline IPI00215637 & ATP-dependent RNA helicase DDX3X & DDX3X & 1.806 & 0.044 & 2.082 & 0.040 \\
\hline IPI00018246 & Hexokinase-1 & HK1 & 2.727 & 0.002 & 3.268 & 0.002 \\
\hline IPI00879004 & DNA topoisomerase 2-alpha & TOP2A & 2.374 & 0.006 & 2.753 & 0.008 \\
\hline IPI00034159 & V-type proton ATPase subunit d 1 & ATP6V0D1 & 1.803 & 0.045 & 2.069 & 0.041 \\
\hline IPI00423570 & GTPase Kras & KRAS & 5.210 & 0.001 & 7.269 & 0.001 \\
\hline IPI00293073 & Mitofusin-1 & MFN1 & 0.696 & 0.035 & 4.734 & 0.001 \\
\hline \multicolumn{7}{|l|}{ H higher } \\
\hline IPI00031691 & 60S ribosomal protein L9 & RPL9 & 1.737 & 0.056 & 2.107 & 0.037 \\
\hline IPI00419258 & High mobility group protein B1protein B1 & HMGB1 & 1.755 & 0.053 & 2.061 & 0.042 \\
\hline IPI00026111 & $\begin{array}{l}\text { Transmembrane and coiled-coil domain- } \\
\text { containing protein } 1\end{array}$ & $\mathrm{TMCO} 1$ & 1.599 & 0.090 & 2.060 & 0.042 \\
\hline IPI00376377 & $\begin{array}{l}\text { Dehydrogenase/reductase (SDR family) } \\
\text { member } 2\end{array}$ & DHRS2 & 1.493 & 0.128 & 2.076 & 0.040 \\
\hline IPI00374657 & Putative uncharacterized protein VAPA & VAPA & 1.637 & 0.079 & 2.162 & 0.033 \\
\hline IPI00418169 & $\begin{array}{l}\text { Putative uncharacterized protein } \\
\text { DKFZp686P03159 }\end{array}$ & ANXA2 & 1.395 & 0.175 & 2.468 & 0.016 \\
\hline IPI00293564 & $\begin{array}{l}\text { Hydroxymethylglutaryl-CoA lyase, } \\
\text { mitochondrial }\end{array}$ & HMGCL & 1.032 & 0.485 & 3.781 & 0.001 \\
\hline IPI00554481 & 4F2 cell-surface antigen heavy chain & SLC3A2 & 1.611 & 0.086 & 2.490 & 0.015 \\
\hline IPI00329600 & Probable saccharopine dehydrogenase & SCCPDH & 1.271 & 0.256 & 2.036 & 0.044 \\
\hline IPI00293845 & Telomere-associated protein RIF1 & RIF1 & 1.490 & 0.129 & 2.301 & 0.023 \\
\hline IPI00478810 & Ribosomal protein S10 & RPS10 & 0.928 & 0.328 & 2.279 & 0.025 \\
\hline IPI00293260 & DnaJ homolog subfamily $\mathrm{C}$ member 10 & DNAJC10 & 1.453 & 0.145 & 2.059 & 0.042 \\
\hline IPI00003856 & V-type proton ATPase subunit E 1 & ATP6V1E1 & 1.557 & 0.103 & 5.208 & 0.001 \\
\hline IPI00306667 & 2',3'-cyclic-nucleotide 3'-phosphodiesterase & CNP & 1.335 & 0.210 & 6.639 & 0.001 \\
\hline \multicolumn{7}{|l|}{ M higher } \\
\hline IPI00418414 & $\begin{array}{l}\text { Hexaprenyldihydroxybenzoate } \\
\text { methyltransferase, mitochondrial }\end{array}$ & COQ3 & 10.682 & 0.001 & 1.407 & 0.204 \\
\hline IPI00644079 & Heterogeneous nuclear ribonucleoprotein U & HNRNPU & 1.833 & 0.040 & 1.660 & 0.111 \\
\hline
\end{tabular}

(Continued) 


\begin{tabular}{|c|c|c|c|c|c|c|}
\hline Protein IDs & Protein Names & $\begin{array}{l}\text { Gene } \\
\text { Names }\end{array}$ & $\begin{array}{l}\text { Ratio } M / L \\
\text { Normalized }\end{array}$ & $\begin{array}{c}\text { Ratio } \\
\text { M/L } \\
p \text {-value }\end{array}$ & $\begin{array}{l}\text { Ratio H/L } \\
\text { Normalized }\end{array}$ & $\begin{array}{c}\text { Ratio H/L } \\
p \text {-value }\end{array}$ \\
\hline IPI00604590 & Nucleoside diphosphate kinase & $\begin{array}{l}\text { NME1- } \\
\text { NME2 }\end{array}$ & 3.010 & 0.001 & 1.376 & 0.219 \\
\hline IPI00005202 & $\begin{array}{l}\text { Membrane-associated progesterone receptor } \\
\text { component } 2\end{array}$ & PGRMC2 & 2.794 & 0.001 & 1.936 & 0.057 \\
\hline IPI00291939 & $\begin{array}{l}\text { Structural maintenance of chromosomes } \\
\text { protein 1A }\end{array}$ & SMC1A & 2.020 & 0.021 & 1.527 & 0.153 \\
\hline \multicolumn{7}{|l|}{ H\&M down } \\
\hline IPI00456965 & $\begin{array}{l}\text { Ubiquinone biosynthesis methyltransferase } \\
\text { COQ5, mitochondrial }\end{array}$ & COQ5 & 0.641 & 0.014 & 0.479 & 0.006 \\
\hline IPI00015808 & Nucleolar GTP-binding protein 2 & GNL2 & 0.490 & 0.001 & 0.286 & 0.001 \\
\hline IPI00293975 & Glutathione peroxidase 1 & GPX1 & 0.678 & 0.026 & 0.596 & 0.038 \\
\hline IPI00893857 & $\begin{array}{l}\text { NADH dehydrogenase } 1 \text { alpha subcomplex } \\
\text { subunit } 11\end{array}$ & NDUFA11 & 0.615 & 0.008 & 0.478 & 0.006 \\
\hline IPI00020050 & $\begin{array}{l}\text { Probable ATP-dependent RNA helicase } \\
\text { DDX28 }\end{array}$ & DDX28 & 0.716 & 0.047 & 0.498 & 0.008 \\
\hline IPI00026512 & GTP-binding protein era homolog & ERAL1 & 0.644 & 0.015 & 0.418 & 0.001 \\
\hline IPI00847172 & Peripheral-type benzodiazepine receptor & PBR & 0.589 & 0.005 & 0.473 & 0.005 \\
\hline IPI00032872 & $28 \mathrm{~S}$ ribosomal protein $\mathrm{S} 16$, mitochondrial & MRPS16 & 0.695 & 0.035 & 0.568 & 0.027 \\
\hline IPI00005966 & $\begin{array}{l}\text { NADH dehydrogenase } 1 \text { alpha subcomplex } \\
\text { subunit } 12\end{array}$ & NDUFA12 & 0.662 & 0.020 & 0.554 & 0.021 \\
\hline IPI00219772 & $\begin{array}{l}\text { NADH dehydrogenase } 1 \text { beta subcomplex } \\
\text { subunit } 7\end{array}$ & NDUFB7 & 0.679 & 0.027 & 0.578 & 0.030 \\
\hline IPI00470631 & $\begin{array}{l}\text { Ubiquinone biosynthesis protein } \mathrm{COQ} 9 \text {, } \\
\text { mitochondrial }\end{array}$ & COQ9 & 0.708 & 0.042 & 0.546 & 0.019 \\
\hline IPI00290614 & Endonuclease G, mitochondrial & ENDOG & 0.609 & 0.007 & 0.537 & 0.016 \\
\hline IPI00514501 & Chromosome 1 open reading frame 57 & C1orf57 & 0.693 & 0.034 & 0.546 & 0.019 \\
\hline IPI00333763 & Glutaredoxin-related protein 5 & GLRX5 & 0.584 & 0.004 & 0.545 & 0.019 \\
\hline IPI00024742 & Cytochrome b-c1 complex subunit 8 & UQCRQ & 0.674 & 0.025 & 0.599 & 0.040 \\
\hline IPI00176469 & $\begin{array}{l}\text { Chaperone activity of bc } 1 \text { complex-like, } \\
\text { mitochondrial }\end{array}$ & $\mathrm{CABC} 1$ & 0.502 & 0.000 & 0.593 & 0.037 \\
\hline IPI00010244 & $28 \mathrm{~S}$ ribosomal protein $\mathrm{S} 11$, mitochondrial & MRPS11 & 0.571 & 0.003 & 0.553 & 0.021 \\
\hline IPI00023673 & Galectin-3-binding protein & LGALS3BP & 0.486 & 0.001 & 0.494 & 0.008 \\
\hline IPI00890773 & Protein MTO1 homolog, mitochondrial & MTO1 & 0.642 & 0.014 & 0.559 & 0.023 \\
\hline IPI00738524 & $\begin{array}{l}\text { General transcription factor IIH subunit 2-like } \\
\text { protein }\end{array}$ & GTF2H2 & 0.014 & 0.001 & 0.134 & 0.001 \\
\hline IPI00021785 & $\begin{array}{l}\text { Cytochrome c oxidase subunit } 5 \mathrm{~B}, \\
\text { mitochondrial }\end{array}$ & COX5B & 0.610 & 0.007 & 0.615 & 0.048 \\
\hline IPI00152685 & Tetratricopeptide repeat protein 15 & TTC15 & 0.643 & 0.014 & 0.497 & 0.008 \\
\hline IPI00219381 & $\begin{array}{l}\text { NADH dehydrogenase } 1 \text { alpha subcomplex } \\
\text { subunit } 2\end{array}$ & NDUFA2 & 0.458 & 0.001 & 0.549 & 0.020 \\
\hline \multicolumn{7}{|l|}{ H down } \\
\hline IPI00448630 & Sterile alpha and TIR motif-containing protein 1 & SARM1 & 1.096 & 0.415 & 0.591 & 0.036 \\
\hline
\end{tabular}

(Continued) 


\begin{tabular}{|c|c|c|c|c|c|c|}
\hline Protein IDs & Protein Names & $\begin{array}{l}\text { Gene } \\
\text { Names }\end{array}$ & $\begin{array}{c}\text { Ratio } M / L \\
\text { Normalized }\end{array}$ & $\begin{array}{c}\text { Ratio } \\
\text { M/L } \\
p \text {-value }\end{array}$ & $\begin{array}{c}\text { Ratio } H / L \\
\text { Normalized }\end{array}$ & $\begin{array}{c}\text { Ratio H/L } \\
p \text {-value }\end{array}$ \\
\hline IPI00032560 & Complex I intermediate-associated protein 30 & NDUFAF1 & 0.876 & 0.235 & 0.503 & 0.009 \\
\hline IPI00013679 & $\begin{array}{l}\text { Deoxyuridine } 5^{\prime} \text {-triphosphate } \\
\text { nucleotidohydrolase }\end{array}$ & DUT & 0.868 & 0.223 & 0.491 & 0.007 \\
\hline IPI00217081 & FUN14 domain-containing protein 1 & FUNDC1 & 0.855 & 0.202 & 0.559 & 0.023 \\
\hline IPI00419626 & 39S ribosomal protein L55, mitochondrial & MRPL55 & 1.201 & 0.312 & 0.599 & 0.040 \\
\hline IPI00167638 & GTP-binding protein 10 & GTPBP10 & 0.782 & 0.105 & 0.600 & 0.040 \\
\hline IPI00217871 & Delta-1-pyrroline-5-carboxylate dehydrogenase & ALDH4A1 & 0.993 & 0.451 & 0.594 & 0.038 \\
\hline IPI00008483 & Amine oxidase A & MAOA & 0.800 & 0.126 & 0.547 & 0.019 \\
\hline IPI00037448 & $\begin{array}{l}\text { Glyoxylate reductase/hydroxypyruvate } \\
\text { reductase }\end{array}$ & GRHPR & 0.902 & 0.280 & 0.596 & 0.038 \\
\hline IPI00011276 & 2-oxoisovalerate dehydrogenase subunit beta & BCKDHB & 0.729 & 0.056 & 0.560 & 0.023 \\
\hline \multicolumn{7}{|l|}{$\mathrm{M}$ down } \\
\hline IPI00016443 & Protein EMI5 homolog, mitochondrial & C11 orf79 & 0.433 & 0.001 & 0.830 & 0.269 \\
\hline IPI00830136 & Uncharacterized protein C1orf31 & C1orf31 & 0.692 & 0.033 & 1.025 & 0.468 \\
\hline IPI00215790 & 60S ribosomal protein $\mathrm{L} 38$ & RPL38 & 0.647 & 0.015 & 1.191 & 0.332 \\
\hline IPI00879060 & $\begin{array}{l}\text { 2-amino-3-ketobutyrate coenzyme A ligase, } \\
\text { mitochondrial }\end{array}$ & GCAT & 0.650 & 0.016 & 1.198 & 0.327 \\
\hline
\end{tabular}

$\mathrm{H}$ (K-ras induction for $48 \mathrm{hrs}$ ), M (K-ras induction for $24 \mathrm{hrs),} \mathrm{L} \mathrm{(control} \mathrm{without} \mathrm{induction).}$

Table 2: Percentage of identified mitochondrial proteins based on their biological functions

\begin{tabular}{|l|l|c|c|}
\hline \multicolumn{2}{l}{ Category name (Accession) } & Counts & Percent of total genes \\
\hline 1 & Cell communication (GO:0007154) & 14 & $11.60 \%$ \\
\hline 2 & Cellular process (GO:0009987) & 13 & $20.30 \%$ \\
\hline 4 & Transport (GO:0006810) & 1 & $18.80 \%$ \\
\hline 5 & Cellular component organization (GO:0016043) & 3 & $1.40 \%$ \\
\hline 6 & Apoptosis (GO:0006915) & 1 & $4.30 \%$ \\
\hline 7 & System process (GO:0003008) & 2 & $1.40 \%$ \\
\hline 8 & Response to stimulus (GO:0050896) & 2 & $2.90 \%$ \\
\hline 9 & Developmental process (GO:0032502) & 9 & $2.90 \%$ \\
\hline 10 & Generation of precursor metabolites and energy (GO:0006091) & 36 & $13.00 \%$ \\
\hline 11 & Metabolic process (GO:0008152) & 4 & $52.20 \%$ \\
\hline 12 & Cell cycle (GO:0007049) & 3 & $5.80 \%$ \\
\hline 13 & Immune system process (GO:0002376) & 4 & $4.30 \%$ \\
\hline
\end{tabular}


Table 3: Differential expression of mitochondrial respiratory chain subunits after K-ras induction for $48 \mathrm{hrs}$

\begin{tabular}{|c|c|c|c|c|c|}
\hline Protein IDs & Gene Names & Protein description & $\begin{array}{l}\text { Mitochondria } \\
\text { location }\end{array}$ & $\begin{array}{l}\text { Ratio H/L } \\
\text { Normalized }\end{array}$ & $\begin{array}{l}\text { Ratio } H / L p \\
\text { value }\end{array}$ \\
\hline IPI00032560 & NDUFAF1 & $\begin{array}{l}\text { NADH dehydrogenase } 1 \text { alpha } \\
\text { subcomplex, assembly factor } 1\end{array}$ & Complex I & 0.50267 & 0.01 \\
\hline IPI00893857 & NDUFA11 & $\begin{array}{l}\text { NADH dehydrogenase } 1 \text { alpha } \\
\text { subcomplex subunit11 }\end{array}$ & Complex I & 0.47817 & 0.01 \\
\hline IPI00219381 & NDUFA2 & $\begin{array}{l}\text { NADH dehydrogenase } 1 \text { alpha } \\
\text { subcomplex subunit } 2\end{array}$ & Complex I & 0.54878 & 0.02 \\
\hline IPI00005966 & NDUFA12 & $\begin{array}{l}\text { NADH dehydrogenase } 1 \text { alpha } \\
\text { subcomplex subunit } 12\end{array}$ & Complex I & 0.55382 & 0.02 \\
\hline IPI00219772 & NDUFB7 & $\begin{array}{l}\text { NADH dehydrogenase } 1 \text { beta } \\
\text { subcomplex subunit } 7\end{array}$ & Complex I & 0.578 & 0.03 \\
\hline IPI00024742 & UQCRQ & Complex III subunit 8 & Complex III & 0.59858 & 0.04 \\
\hline IPI00021785 & COX5B & $\begin{array}{l}\text { Cytochrome c oxidase subunit } 5 \mathrm{~B} \text {, } \\
\text { mitochondria }\end{array}$ & Comolex IV & 0.6149 & 0.04 \\
\hline
\end{tabular}

and $48 \mathrm{hrs}$, respectively (Figure 4A). Western blot analysis also demonstrated a significant decrease of NDUFAF1 expression after K-Ras induction at both time points (24 and $48 \mathrm{~h}$ ), and such decrease was consistently observed in cells with long-term ( $>1$ month) K-Ras induction (Figure 4B). Importantly, doxycycline induced K-Ras ${ }^{\mathrm{G} 12 \mathrm{~V}}$ expression in a dose-dependent manner, and the level of NDUFAF1 protein decreased as the expression of K-Ras increased. In addition, K-Ras expression caused a decrease in NDUFAF1 protein under hypoxia condition, which mimics the tumor microenvironment (Supplemental Figure 1). The expression of NDUFAF1 was also tested in K-Ras transformed human pancreatic ductal epithelial (HPDE/K-Ras) cells established previously [15], and the immunoblotting results showed that NDUFAF1 was significantly decrease in the transformed cells compared with the non-transformed parental HPDE cells (Figure 4B, lower panel).

Considering that oncogenic mutations of K-Ras are frequently observed in the vast majority of human pancreatic cancer cases [16], we next tested if the findings from our proteomic analysis in cell lines could be verified in pancreatic tumor samples, using a pancreatic cancer tissue arrays containing 80 pairs of pancreatic ductal carcinoma and the adjacent normal pancreatic tissues. As shown in Figure 4C, immunohistochemical analysis revealed that the majority $64 \%(51 / 80)$ of the pancreatic cancer tissues exhibited low expression of NDUFAF1. In contrast, the majority of the adjacent normal pancreatic tissues $61 \%(49 / 80)$ showed high expression of NDUFAF1. Overall, there was a statistically lower expression of NDUFAF1 in pancreatic carcinoma than in normal pancreatic tissues $(P<0.05$, Fisher's exact test), suggesting that a decrease in NDUFAF1 expression may be clinically relevant in pancreatic cancer.

\section{Role of NDUFAF1 down-regulation in mediating mitochondrial dysfunction induced by K-Ras}

To further test the functional consequence of NDUFAF1 down-regulation, we used siRNA to specifically knock down the expression of NDUFAF1 in T-Rex/293 cells. As shown in Figure 5A, siRNA against NDUFAF1 effectively suppressed its expression, leading to a significant decrease of the activity of mitochondrial respiratory chain complex I. Because NDUFAF1 is a complex I assembly factor, a Blue-native Polyacrylamide Gel Electrophoresis (BN-PAGE) was performed to detect the effect of knockdown of NDUFAF1 or K-Ras activation. Both K-Ras activation and knockdown of NDUFAF1 mainly inhibited the assembly of complex I (Supplemental Figure 3). As a result, the mitochondrial respiratory chain activity was significantly inhibited, as evidenced by a decrease in oxygen consumption rate (Figure 5B). Because mitochondrial respiratory chain is the major site of ATP generation and reactive oxygen species (ROS) production, we also analyzed the possible metabolic alterations after NDUFAF1 knockdown. Suppression of NDUFAF1 expression by siRNA caused a significant decrease in ATP generation (Figure 5C) and a substantial increase of ROS level detected by both DCFDA (Figure 5D) and MitoSOX (Supplemental Figure 2B). Taken together, these data suggest that suppression of NDUFAF1 expression could cause significant mitochondrial dysfunction.

We then further analyzed the effect of K-Rasmediated mitochondrial dysfunction on glycolytic activity. Figure 6A shows a significant elevation of glycolytic activity in T-Rex/293 cells after short-term (24-48 h) or long term (>1 month) induction of K-Ras expression. 
A

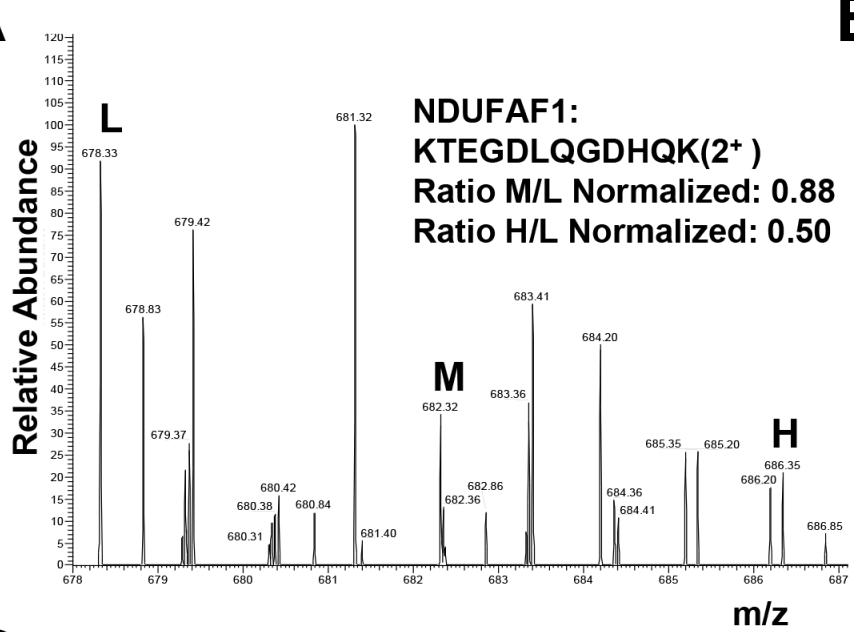

B

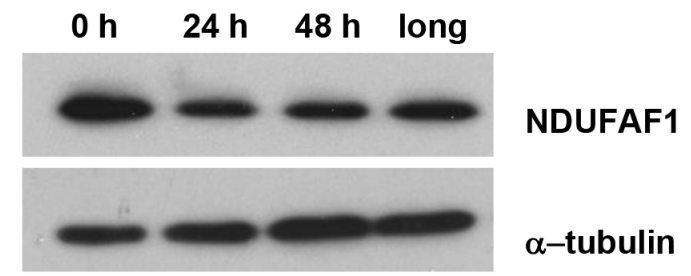

HPDE HPDE/K-Ras

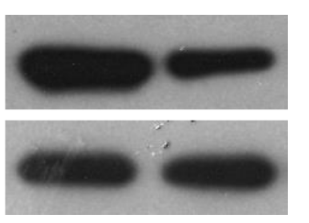

NDUFAF1

$\alpha$-tubulin

\section{C}
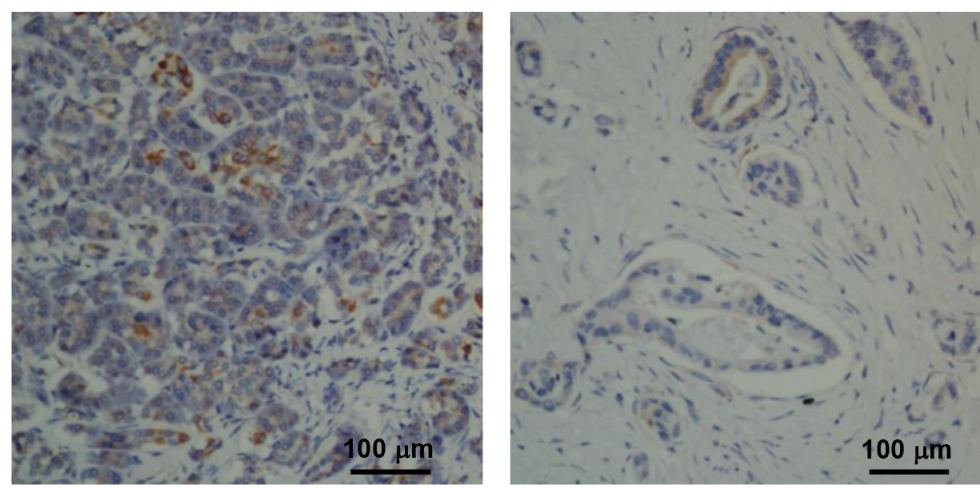

\section{Specimen \\ (n) \\ NDUFAF1}

Carcinoma 80

51

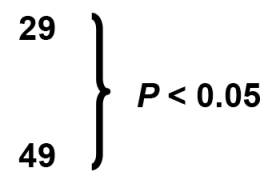

Figure 4: Suppression of NDUFAF1 expression by K-Ras ${ }^{\mathrm{G} 12 \mathrm{~V}}$ and its low expression in pancreatic cancer tissues. (A) Quantification of NDUFAF1 proteins by mass spectrum from three samples. L, control without K-Ras induction. M, K-Ras induction for $24 \mathrm{hrs}$. H, K-Ras induction for $48 \mathrm{hrs}$. (B) Westernblot detection of NDUFAF1 protein in T-Rex/293 cells before and after K-Ras induction and comparison of NDUFAF1 protein in the K-Ras transformed human pancreatic ductal epithelial (HPDE) cells and the parental control. Long, K-Ras induction $>1$ month. (C) Representative immunohistochemical staining of tissue microarray showing NDUFAF1 expression is significantly down regulated in pancreatic cancer tissues. Left panel, normal pancreatic duct; Right panel, pancreatic ductal carcinoma. The comparison of NDUFAF1 expression between normal and cancer tissue was analyzed with Fisher's exact test, $P<0.05 . n=80$.

Since our mitochondrial proteomic analysis identified NDUFAF1 as an important protein suppressed by K-Ras, we tested if knockdown of NDUFAF1 could also cause increase of glycolytic activity. In agreement with the metabolic alterations induced by K-Ras, suppression of NDUFAF1 expression also caused a significant increase in glycolysis, as revealed by the increase in glucose uptake and lactate production (Figure 6B). To further confirm that the increased of glycolysis is a consequence of mitochondrial dysfunction, we used rotenone, a specific inhibitor of mitochondria complex I, to test its effect on glycolysis. As shown in Figure 6C, incubation of T-Rex/293 cells with $10 \mathrm{nM}$ rotenone for $12 \mathrm{hrs}$ caused a significant increase in glucose uptake and lactate production, comparable to that seen in the T-Rex/293 cells with NDUFAF1 knockdown by siRNA (Figure 6B).

The above results showed that acute induction of K-Ras caused mitochondrial dysfunction and metabolic switch to glycolysis. We then further analyzed the metabolic state of cells after long-term induction of K-Ras. Mitochondrial respiratory chain activity remained inhibited in T-Rex/293 cells with continuous induction of K-Ras for more than 1 month (Figure 6D), while glycolytic activity also remained upregulated (Figure 6A, column indicated with "long"). Interestingly, in contrast to the acute ATP decrease after K-Ras induction for 24$48 \mathrm{hrs}$, the cellular ATP level recovered to normal levels after long-term induction of K-Ras for more than 1 month (Figure 6E), suggesting the eventual metabolic adaptation that compensate ATP generation.

$\mathrm{NADH}$ is the main substrate for mitochondrial respiratory chain, and mitochondrial dysfunction could cause an accumulation of NADH. NADH is required for regeneration of $\mathrm{NAD}^{+}$, which is important to maintain active glycolysis [17]. Indeed, we observed that activation of K-Ras for 24 hrs (Figure 6F) or suppression of NDUFAF1 by siRNA (Figure $6 \mathrm{G}$ ) led to an increase of NADH by approximately $20 \%$ in T-Rex/293 cells. Together, these 


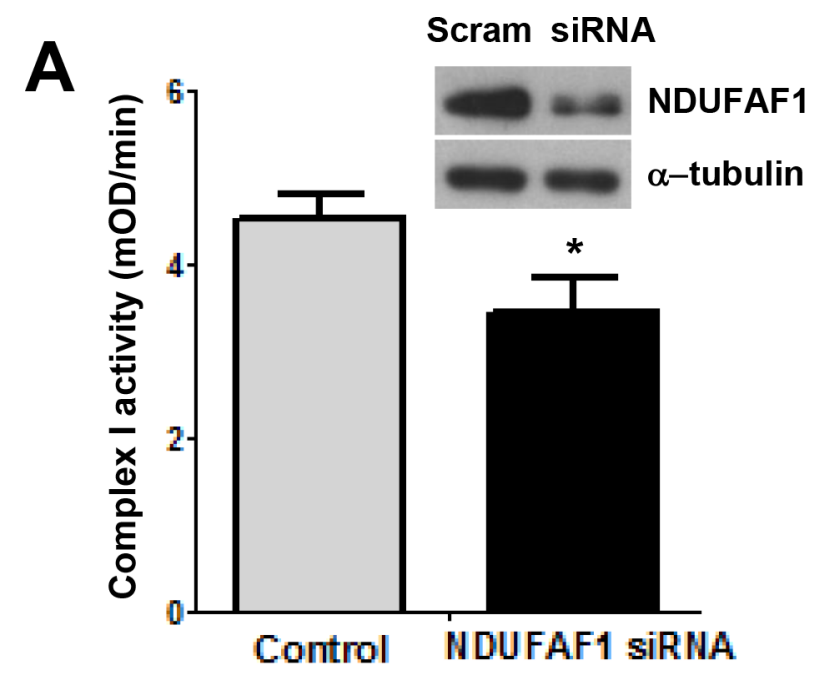

B

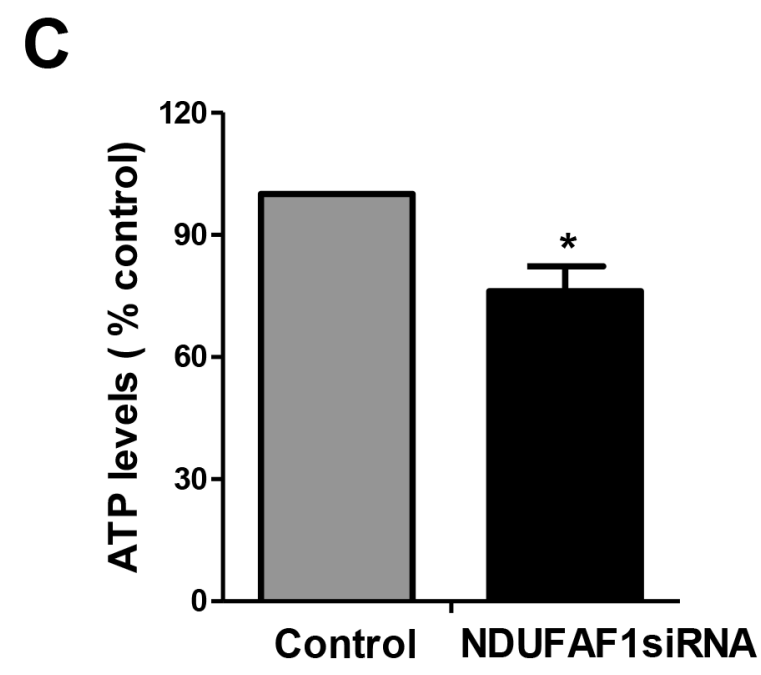

D
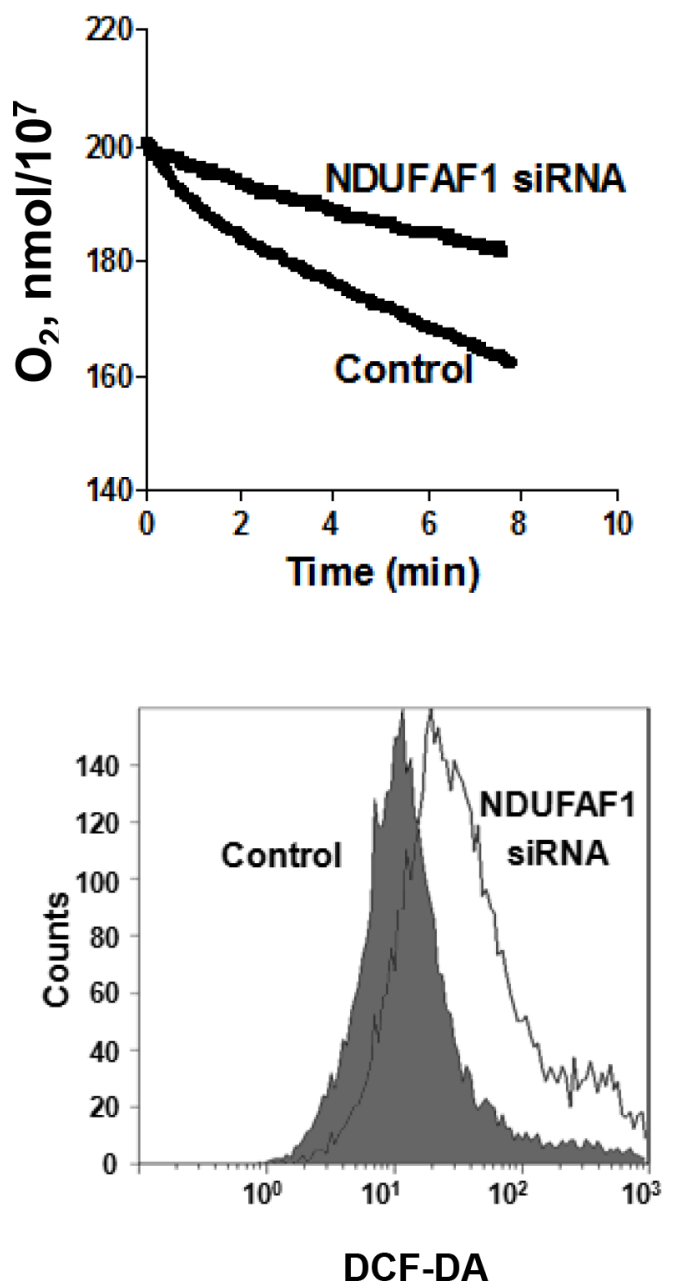

Figure 5: Knockdown of NDUFAF1 causes mitochondrial dysfunction. (A) Inhibition of mitochondrial respiratory chain complex I activity by knockdown of NDUFAF1. Data are shown as mean $\pm \mathrm{SD},{ }^{*} P<0.05$. Western blot analysis showing knockdown efficiency of NDUFAF1. Non-targeting control siRNA (Scram) was used as control. (B) Decrease of oxygen consumption rate after knockdown of NDUFAF1. (C) Decrease of ATP production after NDUFAF1 knockdown, $* P<0.05$. (D) Detection of ROS level before and after knockdown of NDUFAF1 by flow cytometry using CM-DCFDA.

data suggest that down-regulation of NDUFAF1 might be an important event contributing to K-Ras-induced mitochondrial dysfunction and increase in glycolysis.

\section{DISCUSSION}

$\mathrm{K}$-Ras represents the most frequent mutation during malignant transformation and cancer development [18]. Increasing evidence suggests a strong association between oncogenic transformation and metabolic alterations including mitochondrial dysfunction and upregulation of aerobic glycolysis [8, 19, 20]. Our previous study demonstrated that activation of mutated K-Ras (G12V) inhibited the function of mitochondrial respiratory chain, leading to an increase of glycolytic activity [9]. In order to thoroughly understand the molecular mechanisms associated with K-Ras oncogenic signaling and alterations in cellular metabolism, the current study used a subcellular proteomic strategy to identify changes of proteins in the mitochondria of K-Ras transformed cells with SILAC/LC-MS analysis.

By comparing the mitochondrial proteome of T-Rex/293 cells before and after K-Ras induction in the doxycyline inducible cell system, we were able to detect 614 mitochondrial proteins, and among them we identified 70 proteins with significant altered abundance. The biological function analysis revealed that $65 \%$ of the altered mitochondrial proteins were associated with generation of metabolites and metabolic process. Intriguingly, we found that 7 out of the 70 proteins with change in expression were subunits of the mitochondrial respiratory chain complexes, and 5 out of 7 subunits identified belong to complex I. 

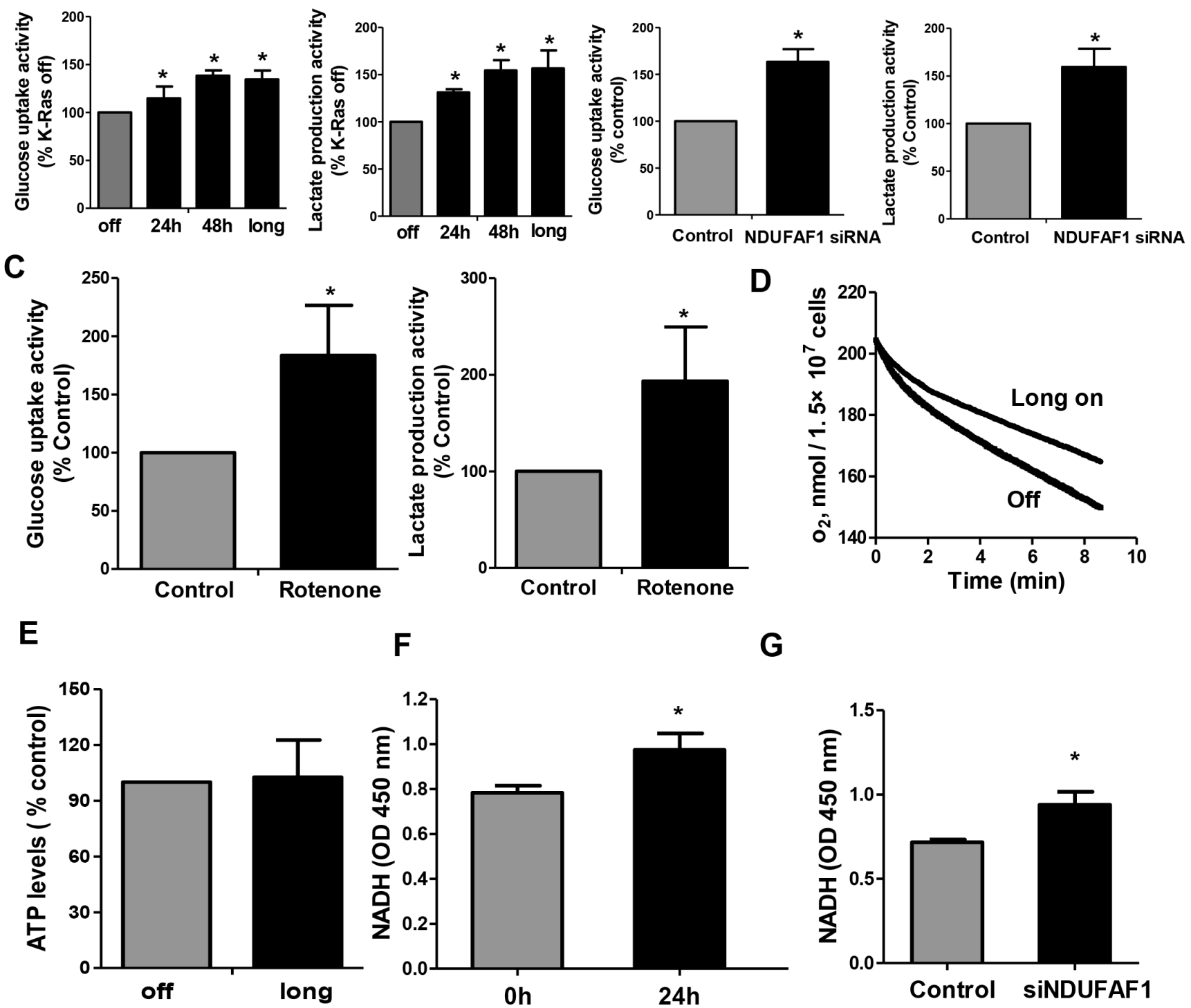

\section{$\mathbf{G}$}

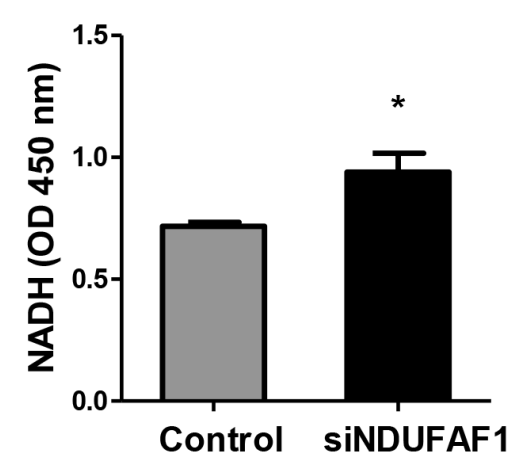

Figure 6: Mitochondrial dysfunction leads to increase of glycolysis activity and accumulation of NADH in T-Rex/293 cells. (A-B) K-Ras activation and knockdown of NDUFAF1 caused increase of glycolytic activity as measured by glucose uptake and lactate production. Long, K-Ras induction for more than 1 month by addition of doxycycline. (C) Inhibitor of mitochondrial respiratory chain complex I by rotenone $(10 \mathrm{nM})$ caused increase of glycolytic activity in TRex/293 cells. (D) Oxygen consumption remained inhibited after long term induction of K-Ras ( $>1$ month). (E) ATP production remained unchanged after long term induction of K-Ras. (F-G) Activation of K-Ras for $24 \mathrm{~h}$ and knockdown of NDUFAF1 caused increase of NADH generation.

Mitochondria are the major source of cellular ATP production. The mitochondrial respiratory chain produces ATP through oxidative phosphorylation. Complex I (NADH dehydrogenase) initiates the electron transportation by oxidizing $\mathrm{NADH}$ to $\mathrm{NAD}^{+}$. Our results showed that a majority of the complex I subunits including NDUFA2, NDUFA11, NDUFA12, NDUFB7, NDUFAF1 were substantially down-regulated $(50 \%)$ after K-Ras ${ }^{\mathrm{G} 12 \mathrm{~V}}$ induction (Table 3), consistent with our previous finding that K-Ras activation inhibited activity of complex I [9]. K-Ras mutation is frequently observed in pancreatic cancer. Our immunohistochemistry analysis revealed that the majority of pancreatic carcinoma tumor tissues exhibited lower expression of NDUFAF1 compared with the normal tissue, suggesting that the down-regulation of NDUFAF1 is likely clinically relevant. Our results also suggest that disruption of complex I may play a major role in mediating suppression of mitochondrial respiration induced by K-Ras ${ }^{\mathrm{G} 12 \mathrm{~V}}$. Although $\mathrm{K}$-Ras represents the most frequent mutation observed in human cancer, several mutations to Ras can transform 
normal cells to cancer. While K-Ras mainly affects complex I assembly of mitochondrial respiratory chain, the effect of $\mathrm{H}$-ras on mitochondrial respiration remain to be determined. Yang et al. showed that oncogenic H-ras ${ }^{\mathrm{Q} 61 \mathrm{~L}}$ transformation caused defects of mitochondrial respiration in NIH-3T3 cells [21]. In contrast, Telang et al. demonstrated that introduction of activated H-ras ${ }^{\mathrm{V} 12}$ into immortalized human bronchial epithelial cells increased tricarboxylic acid cycle activity, oxygen consumption and energetic reliance on electron transport. These contrasting models suggest that the effect of oncogenic Ras on mitochondrial respiration may be context dependent.

However, the precise mechanism of inhibition of NDUFAF1 by K-Ras activation remains unclear at the present time. Ecsit is a cytosolic adaptor protein essential for inflammatory response. It has been reported that Ecsit can localize to mitochondria where it interacts with chaperone NDUFAF1 and functions in complex I assembly. The knockdown of Ecsit in mitochondria results in NDUFAF1 decrease and impaired complex I assembly [22]. Our previous studies have demonstrated translocation of K-Ras protein to mitochondria [9]. It would be interesting to further study the possible interaction of K-Ras and Ecsit and the effect on complex I assembly. In addition, the sequence analysis of human NDUFAF1 promoter revealed several putative TR4-hormone response elements and a chromatin immunoprecipitaiton (ChIP) assay has demonstrated NDUFAF1 is a directly target of TR4 [23]. The potential regulation of TR4 by K-Ras is worth further study.

The association of oncogenes and upregulation of glycolysis has been proposed for some time, although the underlying molecular mechanism still remains to be investigated. Because complex I initiates the electron transportation by oxidizing $\mathrm{NADH}$ to $\mathrm{NAD}^{+}$, here we found that inhibition of NDUFAF1 by activation of K-Ras resulted in accumulation of NADH. Because reoxidization of $\mathrm{NADH}$ is required to maintain proper $\mathrm{NADH} / \mathrm{NAD}^{+}$ ratio and redox homeostasis, the accumulated $\mathrm{NADH}$ after $\mathrm{K}$-Ras activation could be converted to $\mathrm{NAD}^{+}$by redoxregulatory enzymes such as NAD(P)H Oxidase (NOX). Indeed, the regeneration of $\mathrm{NAD}^{+}$is important to maintain active glycolysis. Our previous studies demonstrated that $\mathrm{K}$-Ras activation or dysfunction of mitochondrial leads to up-regulation of NOX [9, 17]. Overexpression or elevated activity of NOX has also been reported in various cancer types including pancreatic cancer [17, 24, 25]. Although the focus of Warburg effect has been energy-centric, recent studies have suggested that the reprogrammed metabolism may be essential for macromolecular biosynthesis [26]. For instance, the tumor-specific form of pyruvate kinase (PKM2) increases the incorporation of glucose carbons into lipids [27]. Ying et al. reported that KrasG12D enhanced glycolytic flux into the pentose phosphate pathway without affecting TCA cycle [28]. Therefore, the decrease of NDUFAF1 observed in our model and pancreatic cancer specimen may indicate metabolic reprogramming driven by K-Ras oncogenic activation.
In summary, this study used SILAC analysis to reveal mitochondrial proteomic changes associated with mitochondrial dysfunction and metabolic alterations induced by oncogenic K-Ras ${ }^{\mathrm{G} 12 \mathrm{~V}}$. Our results suggest that inhibition of mitochondrial respiratory chain complex I may significantly contribute to mitochondrial dysfunction and up-regulation of glycolytic activity during K-Rasmediated transformation and metabolic "reprogramming". Suppression of NDUFAF1 expression and down regulation of other mitochondrial respiratory chain complex components may be important events contributing to K-Rasinduced mitochondrial dysfunction. The mechanisms by which K-Ras activation leads to down-regulation of mitochondrial respiratory chain components currently remain unclear and require further investigation.

\section{METHODS}

\section{Cell culture and stable isotope labeling}

The doxycycline inducible T-Rex/293 cells were established as previously described [9]. T-Rex/K-Ras cells were cultured in Dulbecco's modified Eagle's medium supplemented with $10 \%$ tetracycline free fetal bovine serum. The medium without isotope and labeled with L-Arginine (R0) $(84 \mathrm{mg} / \mathrm{ml})$ or L-lysine (K0) (146 mg/ $\mathrm{ml})$ was considered as "light" (L) medium. The medium containing L- $\left[{ }^{13} \mathrm{C}_{6}\right]$ arginine (R6) and L-4,4,5,5-D -lysine (K4) (Sigma Aldrich) was considered as "medium" (M) medium. The medium containing $\mathrm{L}-\left[{ }^{13} \mathrm{C}_{6},{ }^{15} \mathrm{~N}_{4}\right]$ arginine (R10) and L- $\left[{ }^{13} \mathrm{C}_{6},{ }^{15} \mathrm{~N}_{2}\right]$ lysine (K8) was considered as "heavy" (H) medium. T-Rex/K-Ras cells were cultured in SILAC medium for ten passages to ensure complete incorporation of isotopic amino acids. Cells were then induced by doxycycline for $24 \mathrm{hrs}$ in M medium and 48 hrs in $\mathrm{H}$ medium. Cells without addition of doxycyline were cultured in L medium. HPDE cells and HPDE/K-Ras cells were cultured in DMEM/F12 medium.

\section{Mitochondria isolation}

Mitochondria of T-Rex/293 cells were isolated using Q-proteome Mitochondria Isolation kit (Qiagen). Briefly, cells were washed and re-suspended in lysis buffer and centrifuged at $1000 \times \mathrm{g}$ for $10 \mathrm{mins}$. The pellet was then re-suspended in Disruption Buffer and passed through a syringe 10 times, and re-centrifuged at 1000 $\times \mathrm{g}$ for 10 mins to remove the nuclei, cell debris, and unbroken cells. The supernatant containing mitochondria and the microsomal fraction was centrifuged at 6000 $\times \mathrm{g}$ for 10 mins to collect mitochondria pellet. After removal of the supernatant, the crude mitochondria pellet was re-suspended in Mitochondria Purification Buffer. The purified mitochondria were isolated by density gradient centrifugation. Finally, the mitochondria were re-suspended in lysis buffer containing $8 \mathrm{M}$ urea, 4\% CHAPS, $65 \mathrm{mM}$ DTT, and $40 \mathrm{mM}$ Tris and sonicated at 
100 watts for $30 \mathrm{~s}$. The sample was then centrifuged at $25,000 \times \mathrm{g}$ for $30 \mathrm{mins}$ and the supernatant was collected as the mitochondrial protein lysates.

\section{LC-MS analysis}

Same amount of mitochondria labeled with different isotypes were mixed and separated by one-dimensional SDS-PAGE. The gel was stained with coomassie blue R-250 and cut into 40 slices. The gel slices were then subjected to in-gel digestion with trypsin. Extraction and concentration of the samples for MS analysis were carried out as described previously [29, 30].

Trypsin-digested peptides were separated by HPLC system (Thermo Scientific). The sample was eluted onto a $\mathrm{C}_{18}$ nanocolumn $(0.1 \mathrm{~mm}$ inner diameter $\times 10 \mathrm{~cm}$ long, Michrom Bioresources) using $0.1 \%$ formic acid in water as mobile phase A and $0.1 \%$ formic acid in $80 \%$ acetonitrile as mobile phase B. A linear gradient of $5-35 \%$ solvent B ( $90 \%$ acetonitrile with $0.1 \%$ formic acid) was eluted over $120 \mathrm{mins}$ with a constant flow of $300 \mathrm{nl} / \mathrm{min}$. The HPLC system was coupled to a linear ion trap-orbitrap hybrid mass spectrometer (LTQ-OrbitrapXL, Thermo Scientific) via a nanoelectrospray ion source (Proxeon Biosystems). The spray voltage was $1.2 \mathrm{kV}$, and the temperature of the heated capillary was $200^{\circ} \mathrm{C}$. The full-scan mass range was from $\mathrm{m} / \mathrm{z}$ 400-2000 with resolution 60,000 at $\mathrm{m} / \mathrm{z} 400$. The five most intense ions were sequentially isolated for fragmentation in the linear ion trap by collision-induced dissociation. Maximal filling times were $1,000 \mathrm{~ms}$ for the full scans and $150 \mathrm{~ms}$ for the MS/MS scans. The dynamic exclusion list was restricted to a maximum of 500 entries with a maximum retention period of $90 \mathrm{~s}$ and a relative mass window of $10 \mathrm{ppm}$.

\section{MS data analysis}

The MS/MS peak list was generated by Xcalibur software (Thermo Scientific) and analyzed with MaxQuant (Version, 1.0.13.13). The output files were submitted to Mascot (Version 2.2, Matrix Science) for peptide and protein identification. Searches were conducted against target-decoy human MaxQuant (ipi.HUMAN.v3.52. decoy). Enzyme specificity was set to that of trypsin, allowing for $\mathrm{N}$-terminal cleavage to proline and between aspartic acid and proline. Searches were performed with a MS tolerance of $20 \mathrm{ppm}$ and a fragment tolerance of 0.5 Da. Carboxyamidomethylated cysteine was used as a fixed modification. Variable modifications included methionine oxidation and protein N-terminal acetylation. Peptides with minimum of 6 amino acids were allowed for analysis and proteins were identified if they had at least one unique peptide. The results were reported with $5 \%$ peptide false discovery rate and $1 \%$ protein false discovery rate. The posterior error probabilities (PEP, false hit probability given the peptide score and length) should be below or equal to 0.01 . The sequences corresponding to the 760 protein entries were searched in the database.

\section{Antibodies and RNA interference}

The following antibodies were used for immunoblotting analysis: K-Ras, Cytochorme C and NDUFAF1 (Abcam), tubulin, VDAC and Bip (Cell Signaling). The siRNA (Ribobio, Guangzhou, China) target sequence for NDUFAF1 was 5'-GCAAGGAGATCACCAGAAA-3'. A non-specific scramble siRNA was used as control.

\section{Transmission electron microscope}

Samples were prepared as described previously [31]. Briefly, cells were fixed in $2.5 \%$ glutaraldehyde for 2 hours and $1 \%$ osmium tetroxide for another 1 hour. Cells were then dehydrated in a graded series of ethanol and embedded in spurr resin. Sections were prepared and examined with Morgagni transmission electron microscope (FEI).

\section{Immunohistochemistry}

Immunohistochemical staining for NDUFAF1 was performed on the pancreatic cancer tissue microarray (TMA, Shanghai Biochip, Shanghai, China) containing 80 pancreatic ductal carcinoma and 80 paired non-neoplastic pancreatic tissue samples. TMA was deparaffined and endogenous peroxidase activity was blocked with $3 \%$ hydrogen peroxidase. To unmask the immunoepitopes, the slides were immersed in EDTA ( $1 \mathrm{mmol} / \mathrm{L}, \mathrm{pH} 8.0)$ and boiled for 15 minutes. The slides were incubated with NDUFAF1 antibody (Abcam, 1:100 dilution) overnightat at $4^{\circ} \mathrm{C}$ and with secondary antibody at room temperature for 30 mins. Finally, the slides were stained with $3,3^{\prime}$-diaminobenzidine tetrahydrochloride (DAB) for signal detection and counterstained with $20 \%$ hematoxylin. The immunostaining scores were estimated according to the percentage of the staining intensity of the positive cells as described previously [32].

\section{Flow cytometry analysis of reactive oxygen species (ROS)}

Intracellular $\mathrm{ROS}\left(\mathrm{H}_{2} \mathrm{O}_{2}\right)$ contents were measured by incubating cells with $5 \mu \mathrm{M}$ CM-DCFDA (Invitrogen) at $37^{\circ} \mathrm{C}$ for $1 \mathrm{~h}$ followed by detection using flow cytometry (Beckman Coulter). Intracellular superoxide level was measured by incubating cells with $5 \mu \mathrm{M}$ MitoSOX (Invitrogen) at $37^{\circ} \mathrm{C}$ for $1 \mathrm{~h}$ before detection by flow cytometry analysis.

\section{Analysis of oxygen consumption}

As previously described [33], 1 million cells were re-suspended in $1 \mathrm{ml}$ culture medium pre-equilibrated with $21 \%$ oxygen and placed in a sealed respiration chamber (Oxytherm, Hansatech Instrument) to monitor oxygen consumption rate. 


\section{Metabolic measurements}

Glucose uptake and lactate production were measured with Glucose Assay Kit II and Lactate Assay Kit II (Biovision) according to manufacturer's instructions. Aliquots of the medium were removed from cell culture and Glucose uptake and lactate production was determined by the concentration difference between samples and blank medium control. Cellular ATP and NADH contents were measured using the ATP Colorimetric Assay Kit and NADH Quantitation Kit (Biovision) respectively as described before [9].

\section{Enzyme activity of mitochondria complex I}

The activity of mitochondrial complex I was measured using Complex I Enzyme Activity Microplate Assay Kit (Abcam) according to manufacturer's instructions. Briefly, the mitochondrial proteins were extracted and added to the microplate. The complex I enzyme was immune captured within the wells of the microplate, and the activity was determined by the oxidation of NADH to $\mathrm{NAD}^{+}$. Complex I activity was measured by the increase in absorbance of the dye at 450 $\mathrm{nm}$ and shown as the changes in absorbance per minute.

\section{Statistical analysis}

Statistical difference between NDUFAF1 expression of benign and malignant pancreatic tissue on tissue microarray was analyzed by Fisher's exact test. All other statistical significant difference analyses were performed using a two-tailed Student's $t$ test. The data are shown as means $\pm \mathrm{SD} . P<0.05$ was considered statistically significant.

\section{ACKNOWLEDGMENTS}

This work was supported by research grants from the National Natural Science Foundation of China (No. 81101520), National Basic Research Program of China (973 program) 2012CB967004 and 2013CB910304 and Guangdong Natural Science Foundation (No. S2011040004572).

\section{REFERENCES}

1. Hanahan D, Weinberg RA. Hallmarks of cancer: the next generation. Cell. 2011; 144:646-674.

2. Warburg O. On the origin of cancer cells. Science. 1956; 123:309-314.

3. Gatenby RA, Gillies RJ. Why do cancers have high aerobic glycolysis?. Nat Rev Cancer. 2004; 4:891-899.

4. Ferreira LM. Cancer metabolism: the Warburg effect today. Exp Mol Pathol. 2010; 89:372-380.
5. Carew JS, Huang P. Mitochondrial defects in cancer. Mol Cancer. 2002; 1:9.

6. Bivona TG, Quatela SE, Bodemann BO, Ahearn IM, Soskis MJ, Mor A, Miura J, Wiener HH, Wright L, Saba SG, Yim D, Fein A, Perez de Castro I, Li C, Thompson $\mathrm{CB}$, Cox $\mathrm{AD}$, et al. PKC regulates a farnesylelectrostatic switch on K-Ras that promotes its association with Bcl-XL on mitochondria and induces apoptosis. Mol Cell. 2006; 21:481-493.

7. Weinberg F, Hamanaka R, Wheaton WW, Weinberg S, Joseph J, Lopez M, Kalyanaraman B, Mutlu GM, Budinger GR, Chandel NS. Mitochondrial metabolism and ROS generation are essential for Kras-mediated tumorigenicity. Proc Natl Acad Sci U S A. 2010; 107:8788-8793.

8. Chiaradonna F, Gaglio D, Vanoni M, Alberghina L. Expression of transforming K-Ras oncogene affects mitochondrial function and morphology in mouse fibroblasts. Biochim Biophys Acta. 2006; 1757:1338-1356.

9. Hu Y, Lu W, Chen G, Wang P, Chen Z, Zhou Y, Ogasawara M, Trachootham D, Feng L, Pelicano H, Chiao PJ, Keating MJ, Garcia-Manero G, Huang P. $\mathrm{K}-\mathrm{ras}(\mathrm{G} 12 \mathrm{~V})$ transformation leads to mitochondrial dysfunction and a metabolic switch from oxidative phosphorylation to glycolysis. Cell Res. 2012; 22:399-412.

10. Verma M, Kagan J, Sidransky D, Srivastava S. Proteomic analysis of cancer-cell mitochondria. Nat Rev Cancer. 2003; 3:789-795.

11. Dimmer KS, Rapaport D. Proteomic view of mitochondrial function. Genome Biol. 2008; 9:209.

12. Dunning CJ, McKenzie M, Sugiana C, Lazarou M, Silke J, Connelly A, Fletcher JM, Kirby DM, Thorburn DR, Ryan MT. Human CIA30 is involved in the early assembly of mitochondrial complex I and mutations in its gene cause disease. EMBO J. 2007; 26:3227-3237.

13. Vogel RO, Janssen RJ, Ugalde C, Grovenstein M, Huijbens RJ, Visch HJ, van den Heuvel LP, Willems PH, Zeviani M, Smeitink JA, Nijtmans LG. Human mitochondrial complex I assembly is mediated by NDUFAF1. FEBS J. 2005; 272:5317-5326.

14. Vogel RO, van den Brand MA, Rodenburg RJ, van den Heuvel LP, Tsuneoka M, Smeitink JA, Nijtmans LG. Investigation of the complex I assembly chaperones B17.2L and NDUFAF1 in a cohort of CI deficient patients. Mol Genet Metab. 2007; 91:176-182.

15. Qian J, Niu J, Li M, Chiao PJ, Tsao MS. In vitro modeling of human pancreatic duct epithelial cell transformation defines gene expression changes induced by K-ras oncogenic activation in pancreatic carcinogenesis. Cancer Res. 2005; 65:5045-5053.

16. Gibbs JB, Oliff A, Kohl NE. Farnesyltransferase inhibitors: Ras research yields a potential cancer therapeutic. Cell. 1994; 77:175-178.

17. Lu W, Hu Y, Chen G, Chen Z, Zhang H, Wang F, Feng L, Pelicano H, Wang H, Keating MJ, Liu J, McKeehan W, 
Luo Y, Huang P. Novel role of NOX in supporting aerobic glycolysis in cancer cells with mitochondrial dysfunction and as a potential target for cancer therapy. PLoS Biol. 2012; 10:e1001326.

18. Bos JL. ras oncogenes in human cancer: a review. Cancer Res. 1989; 49:4682-4689.

19. Ralph SJ, Rodriguez-Enriquez S, Neuzil J, Saavedra E, Moreno-Sanchez R. The causes of cancer revisited: "mitochondrial malignancy" and ROS-induced oncogenic transformation - why mitochondria are targets for cancer therapy. Mol Aspects Med. 2010; 31:145-170.

20. Ramanathan A, Wang C, Schreiber SL. Perturbational profiling of a cell-line model of tumorigenesis by using metabolic measurements. Proc Natl Acad Sci U S A. 2005; 102:5992-5997.

21. Yang D, Wang M-T, Tang Y, Chen Y, Jiang H, Jones T, Rao K, Brewer G, Singh KK, Nie D. Impairment of mitochondrial respiration in mouse fibroblasts byoncogenic H-RASQ61L. Cancer Biology \& Therapy. 2014; 9:122-133.

22. Vogel RO, Janssen RJRJ, van den Brand MAM, Dieteren CEJ, Verkaart S, Koopman WJH, Willems PHGM, Pluk W, van den Heuvel LPWJ, Smeitink JAM, Nijtmans LGJ. Cytosolic signaling protein Ecsit also localizes to mitochondria where it interacts with chaperone NDUFAF1 and functions in complex I assembly. Genes \& Development. 2007; 21:615-624.

23. Liu S, Lee Y-F, Chou S, Uno H, Li G, Brookes P, Massett MP, Wu Q, Chen L-M, Chang C. Mice Lacking TR4 Nuclear Receptor Develop Mitochondrial Myopathy with Deficiency in Complex, I. Molecular Endocrinology. 2011; 25:1301-1310.

24. Fukuyama M, Rokutan K, Sano T, Miyake H, Shimada M, Tashiro S. Overexpression of a novel superoxide-producing enzyme, NADPH oxidase 1, in adenoma and well differentiated adenocarcinoma of the human colon. Cancer Lett. 2005; 221:97-104.
25. Lim SD, Sun C, Lambeth JD, Marshall F, Amin M, Chung L, Petros JA, Arnold RS. Increased Nox1 and hydrogen peroxide in prostate cancer. Prostate. 2005; 62:200-207.

26. Hsu PP, Sabatini DM. Cancer Cell Metabolism: Warburg and Beyond. Cell. 2008; 134:703-707.

27. Christofk HR, Vander Heiden MG, Wu N, Asara JM, Cantley LC. Pyruvate kinase M2 is a phosphotyrosinebinding protein. Nature. 2008; 452:181-186.

28. Ying H, Kimmelman AC, Lyssiotis CA, Hua S, Chu GC, Fletcher-Sananikone E, Locasale JW, Son J, Zhang H, Coloff JL, Yan H, Wang W, Chen S, Viale A, Zheng H, Paik JH, et al. Oncogenic Kras maintains pancreatic tumors through regulation of anabolic glucose metabolism. Cell. 2012; 149:656-670.

29. Rappsilber J, Ishihama Y, Mann M. Stop and go extraction tips for matrix-assisted laser desorption/ionization, nanoelectrospray, and LC/MS sample pretreatment in proteomics. Anal Chem. 2003; 75:663-670.

30. Shevchenko A, Tomas H, Havlis J, Olsen JV, Mann M. In-gel digestion for mass spectrometric characterization of proteins and proteomes. Nat Protoc. 2006; $1: 2856-2860$.

31. Kelley DE, He J, Menshikova EV, Ritov VB. Dysfunction of mitochondria in human skeletal muscle in type 2 diabetes. Diabetes. 2002; 51:2944-2950.

32. Wang P, Mai C, Wei YL, Zhao JJ, Hu YM, Zeng ZL, Yang J, Lu WH, Xu RH, Huang P. Decreased expression of the mitochondrial metabolic enzyme aconitase (ACO2) is associated with poor prognosis in gastric cancer. Med Oncol. 2013; 30:552.

33. Pelicano H, Feng L, Zhou Y, Carew JS, Hileman EO, Plunkett W, Keating MJ, Huang P. Inhibition of mitochondrial respiration: a novel strategy to enhance druginduced apoptosis in human leukemia cells by a reactive oxygen species-mediated mechanism. J Biol Chem. 2003; 278:37832-37839. 